\title{
Organization of Teaching Contents and Design of Teaching Method for IoT Course Oriented to the Computer Major
}

\author{
Ce Zhang*, Weigong Lv, Jianan Jiang, Yiran Zhao, Dianhui Chu, \\ School of Computer Science and Technology, Harbin Institute of Technology at Weihai, 2 Cultural \\ West Road, 264209 Weihai, Shandong Province, China \\ zhangce@hitwh.edu.cn, Iwgswl@sina.com, susan_jin@163.com, 530634471@qq.com, \\ chudianhui@vip.sina.com
}

Keywords: Computer major, IoT, IoT full stack talent, Teaching method, Technology study roadmap.

\begin{abstract}
How to implement targeted teaching of Internet of Things in computer science education has become the key to cultivate students' ability to solve complex engineering problems represented by Internet of Things system. It puts forward the organization of teaching content and teaching method of computer science and technology. First of all, from the perspective of the layer, function and technology of Internet of things, this paper gives the object network architecture and key point of understanding. From the information acquisition, transmission and processing point of view, it analyzes the lack of knowledge of computer students generally; Based on the proposed goal of the Internet of things talents training and technical learning route, the analysis of the feasibility of the study of the Internet of things courses in computer science and the characteristics of computer, this paper gives a plan for the content of Internet of things in computer science, and analyzes the key points of knowledge teaching of the three levels of the Internet of things. Further, to cultivate students' comprehensive system design and implementation capacity, the teaching route planning chart of the Internet of things is proposed to guide the teaching process. Finally, it is concluded that the total stack of Internet of things can be an important direction and goal of the comprehensive ability of computer system.
\end{abstract}

\section{Introduction}

At present, with the vigorous development of the Internet of things, especially in the construction of national implementation of the "new engineering" [1] [2] [3] and under the background of "six remarkable a top" plan [4], Internet of things has become the new engineering major that many universities focus on. The Internet of things series is gradually becoming the backbone of teaching.

Computer majors have not studied the perception layer technology. They have only studied Internet courses, and lack the fusion knowledge of many technologies in application layer.

Iot systems including comprehensive sense perception layer, network layer of reliable transmission, intelligent application of the application layer, is a large information system, covering the entire IT technology. It is an integrated network that includes the physical world and information world. Therefore, compared with the traditional simple hardware development, software development and network development, it Internet of things era is urgent to plan as a whole the technical development of comprehensive talents, to grasp from the underlying typical intelligent embedded system development to the upper typical intelligent cloud computing system development ability demand is particularly urgent.

Since the beginning of China's Internet of things in 2009, China has conducted preliminary exploration on the teaching and reform of Internet of things, and has achieved some achievements. The literature [5] [6] [7] is aimed at the cultivation of the professional talents of the Internet of 
things, and puts forward the train of thought for the cultivation plan. In the construction of the Internet of things laboratory, literature [8] is a plan for the construction of the Internet of things laboratory in universities. On the reform of practical teaching, literature [9] [10] has made some attempts and explorations on the practice system and mode. Aiming at the talent cultivation strategy of iot, Nanjing University of Posts and Telecommunications started early [11] and gave a framework design and practice. In terms of professional construction and curriculum reform, literatures [12] [13] [14] are designed for the construction of Internet of things and the construction of Internet engineering specialty Internet. These research and practice work of promoted the development of the domestic Internet teaching, but always failed to put forward considering the computer class specialized characteristics of IoT with traction type talent cultivation mode of teaching reform, thus need to be addressed. Based on our previous study of the teaching plan in IoT for software engineering and embedded, this article discusses the IoT design course teaching content organization and teaching method oriented computer major.

\section{Abstract IoT Architecture}

In physical geography, the Internet of things, which started in the sensing network, has expanded beyond the Internet. In terms of thinking cognition, the Internet of things originated from the Internet has developed the ubiquitous application mode. As you can see, the distance between life and IoT is the closest thing for the current computer or IT research.

Based on the large amount of research and teaching work in the early stage, we have refined the IoT architecture and key understanding points shown in Fig.1.

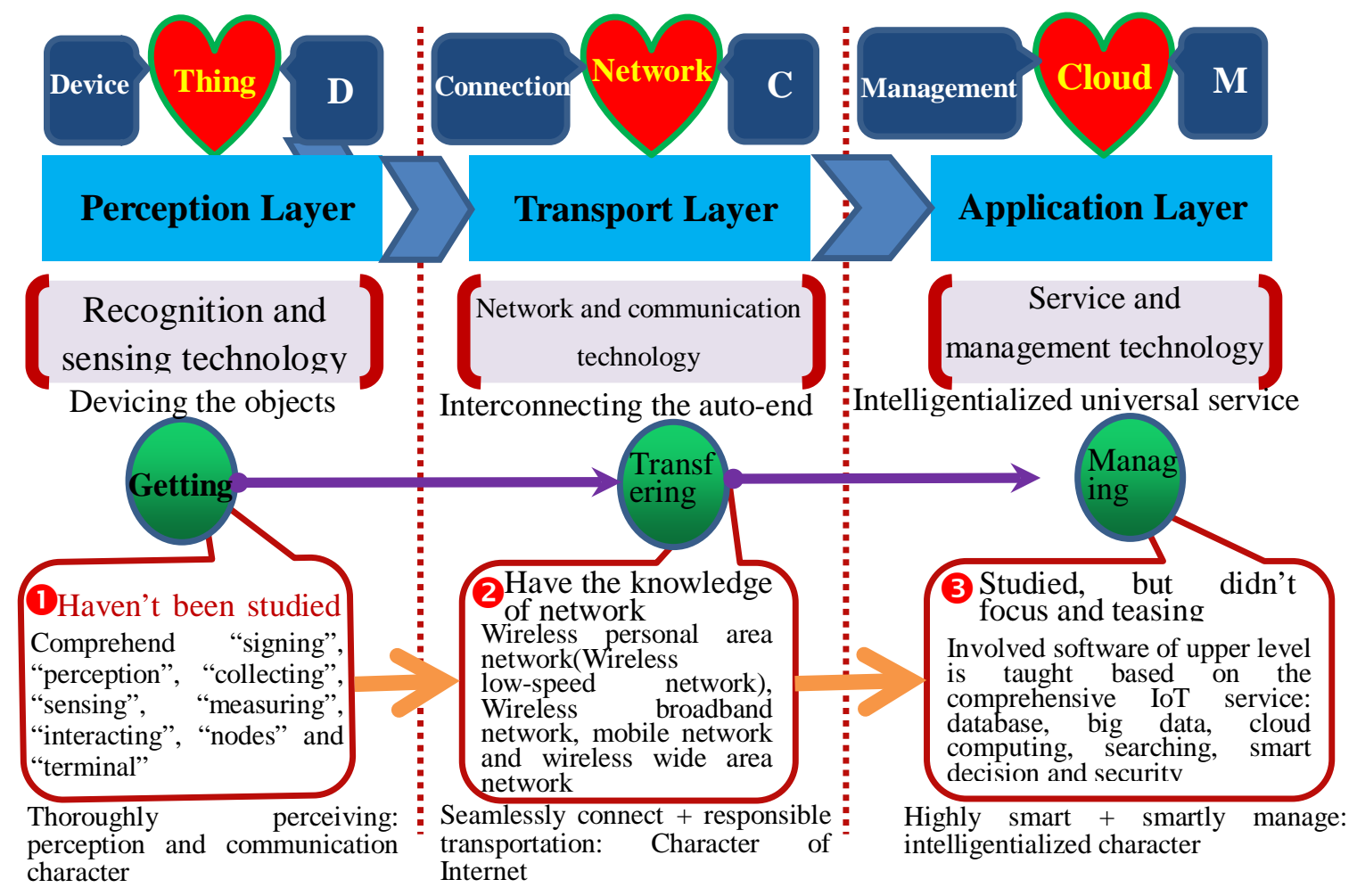

Fig.1. The refined IoT architecture and key understanding points

(1)The "object" includes chips such as RFID, various sensors, MES (Micro-Electro-Mechanical System), intelligent devices and instruments, and other embedded systems with controllers and resident programs.

(2)"Network" covers the underlying perception networks like Zigbee, bluetooth, NFC, wi-fi, 
WiMAX metropolitan area network, 3G / 4G mobile communication network, and the Internet.

(3)"Cloud" is embodied in big data, cloud computing, intelligent search and information security.

Therefore, the Internet of things is a collective of many technologies in the information age, and each individual technology can effectively bring together the economic and social promotion to the architecture of the Internet of things.

The Internet of things has achieved multiple levels of leapfrogging. Based on years of teaching and research practice, we believe that this span includes the following aspects:

(1) From the virtual to the reality: the Internet is based on information inside the computer, while the Internet of things faces the real physical world.

(2) From subjective to objective: the Internet must need the active participation of "people", but the Internet of things can get rid of the active participation of "people" and have autonomous capability;

(3) From macro to micro: the Internet of things can "perceive" micro-transactions, extending the reach of human information to various aspects of the physical world;

(4) From local to ubiquitous: compared to the aggregation of many computers on the Internet, the Internet of things realizes the interconnection of all things, which is far beyond the scope of computers;

(5) From passive to active: the Internet of things can "perceive" the physical world in real time and actively serve human beings;

(6) From the plane to space: the Internet of things can be set in the land and sea, which is widely used in human production and living space;

(7) From semi-automatic to automatically: Internet information mainly comes from artificial information collection after the entry into the computer system into the network, while the Internet of things directly perceives the physical world, realizes the automatic collection, transmission and processing automatically.

(8) From Europe and the United States to China thinking: the Internet of things is integrated into the natural world, integrating technology, people and natural. It has remarkable Chinese thinking, which apparently different from Europe and the United States thinking of computer or the Internet.

In the development of IT technology, the value of Internet of things is far more than other techniques, which might be interpreted as: the Internet of things belonging to manufacturing engineering, is considered a kind of real economy, which have direct promotion effect in transformation and upgrading of manufacturing industry transformation and economy.

\section{Analysis of the feasibility of studying Internet of things courses in computer majors}

With the goal of [15] training, we have established a technical learning route matching the IoT full stack talent training in [16]. Here, the technical learning route is mapped to the specific curriculum setting and the curriculum content system optimization to ensure that the courses can effectively carry the technical learning route and achieve the targeted shooting. From the learning route that from the bottom of embedded system design and development of technology to study upper intelligent application development, we can see that IoT full stack talent cultivation is obvious systematic and have targeted features. With regard to the systematic features, it is reflected in the course learning and practice of the series. And in terms of the target characteristics, it is reflected in the result orientation of the talent demand of the Internet of things. 
In terms of the set of course, IoT full stack talents development is based on the basic computer courses. The basic computer capacity is trained, but IoT and embedded system are the kernel. The necessary technology skill and IoT full stack talents thinking will be developed. On the basis of basic courses and core courses, the proposed course system supporting IoT education is shown in Fig.2. From computer basic
course to IoT core course
Ability development aim of computer major system

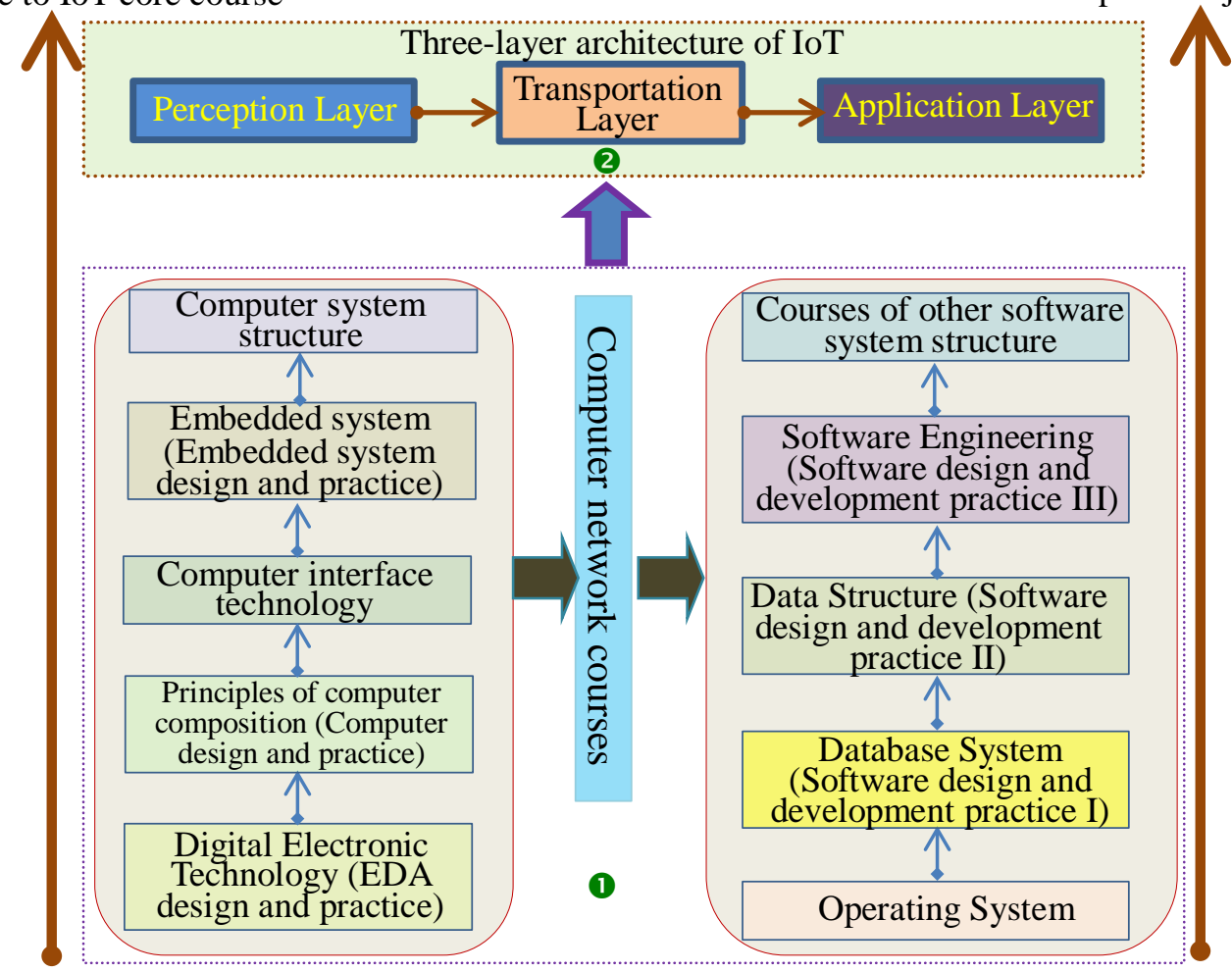

Fig.2. Main courses of computer major support the development of IoT education and full stack talents

It can be seen in the Fig.2, IoT full stack talent development is based on the basic courses of computer major, and the keynote is the IoT and embedded system courses. The former is the basic courses of computer major in the Fig.1. The latter is the core course set of IoT and embedded system. Therefore, computer major students completely have the knowledge structure to study IoT courses, but the teaching contents and design should be directly designed.

\section{IoT teaching contents programming}

Based on the basic character of computer major, the shortage of computer major knowledge system need to be covered in the IoT teaching contents programming. As a result, the following basic knowledge points programming is given. 


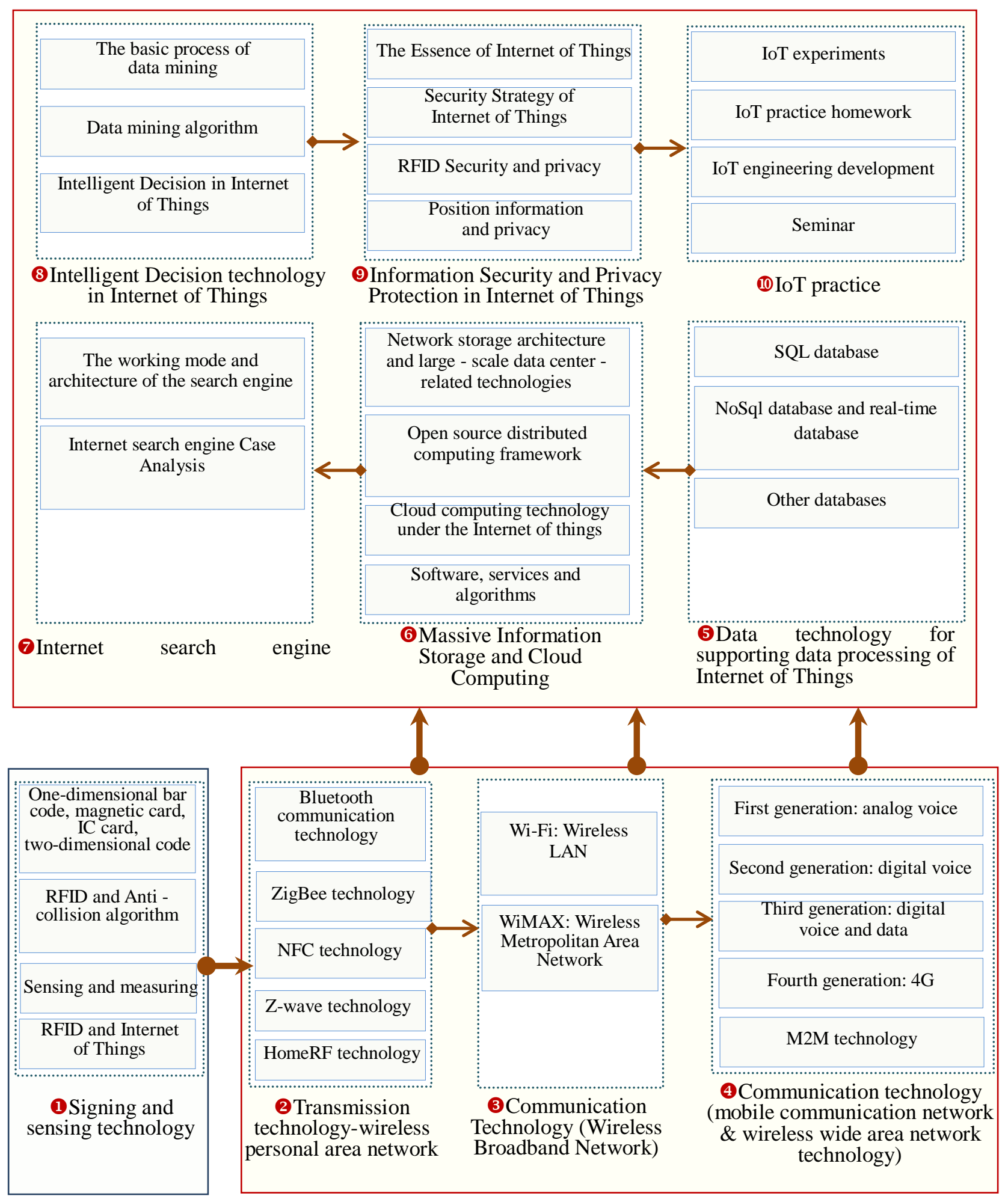

Fig.3. Entire programming of the IoT teaching contents oriented to computer major

The apperceive layer focuses on signing, sensing and measuring technology, which is the shortage of computer major. Network layer focuses on the wireless area network and mobile network, especially mobile network, but the traditional network is ignored. The application layer focuses on NoSql database, cloud computing of IoT, big data, searching engine, smart decision and security skill, which reflects the comprehensive development of applying knowledge.

Accordingly, directed by IoT full stack talent development, the design of teaching content 
concentrates on how to train students solve complex engineering problems with IoT knowledge.

\section{IoT course teaching programming}

Through the previous implement, the IoT full stack talents development directed teaching programming figure is shown in Fig.4. The thread running through the programming figure is the construction of IoT three-layer architecture technology system. The aim is to train students in system design and implementing ability. Through the designing of the technology study line oriented to the knowledge structure of computer major students, IoT course programming and system optimizing, innovation teaching and practice, the program will be gradually put forward.

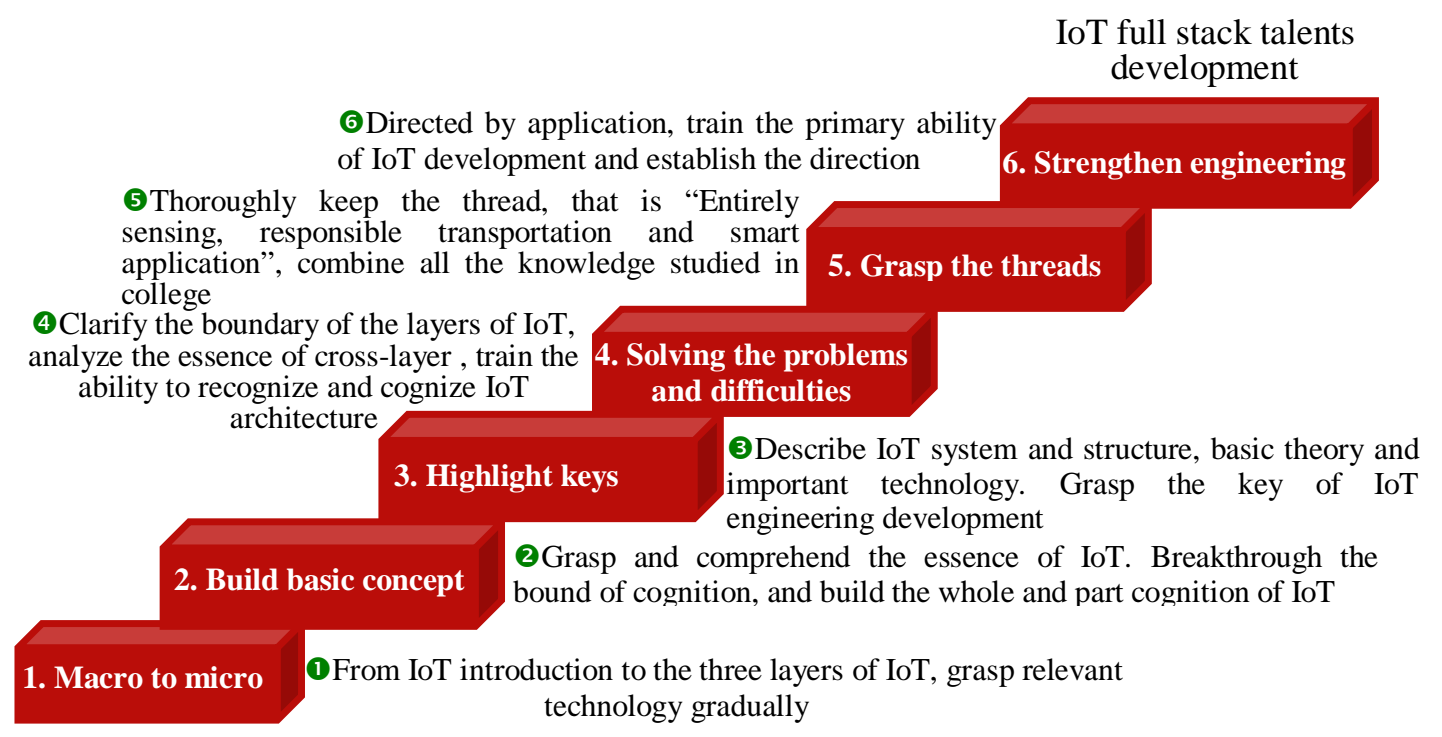

Fig.4. Programming figure of IoT course teaching line

In the process of development of IoT full stack talents for computer major, the main technology thought should be applied to cover the lacked knowledge. The main technology thought is "The apperceive layer focuses on sensing technology $\rightarrow$ Network layer focuses on the wireless area network and mobile network $\rightarrow$ The application layer focuses on cloud computing of IoT, big data, and security skill”. It needs to start from macro to micro. The lacked knowledge of computer major needs to be taught. The coherence and systematic mechanism have to be highlighted. Meanwhile, this program can be transferred to the specific ability of IoT system design and practice, and the knowledge and ability can be reflected and double improved.

Based on the above systematic cognition, the IoT course system has been innovated in the teaching practice in these years. We applied targeted teaching program and reached achievements. Students' ability to solve complex engineering problems is improved, which is proved enough in the part of engineering practice, graduate design and real project development.

\section{Conclusion}

According to the information trend of IoT, the key comprehension points and IoT architecture viewed from computer major are proposed. The feasibility of computer major opening IoT course is analyzed, and teaching contents and teaching line of IoT course are programmed. Finally, it is concluded that targeted and effective IoT education can train students in solving complex engineering problems. Various subjects and professional knowledge are involved in IoT, and the relevant technology is concentrated. How to program the course contents and teaching method is a problem that must be considered in IoT education, and the answer is given in the research. Directed 
by the previously proposed IoT full stack talent development aim and technology study line, the exploration of teaching contents and teaching design of IoT course are given. We hope that it can be a reference and play an important role in training students in solving complex engineering problems.

\section{Acknowledgement}

In this paper, the research was sponsored by the research project of Harbin Institute of Technology at Weihai (Research and practice on IoT full stack talents development pattern) (BK201602) and 2016 Undergraduate College Education Reform Research of Shandong Province, "Research and practice of development pattern for engineering leading talents oriented to the need of top industry talents" (B2016M016). The research was also sponsored by the 2017 industry-education cooperating education project, "Constructing laboratories of Internet of things directed by solving the ability development with complex engineering problems" and 2016 postgraduate education innovation program, "Research on the multiple dimension education quality assessment system oriented to the special master” (SDYZ1603)

\section{References}

[1] Higher Education Department of the Ministry of Education. "New Engineering" Construction Fudan Consensus [J]. Research on Higher Engineering Education, 2017(1).

[2] Higher Education Department of the Ministry of Education. "New engineering" construction action line [J]. Research on Higher Engineering Education, 2017(4).

[3] Higher Education Department of the Ministry of Education. New Engineering Construction Guide [J]. Research on Higher Engineering Education, 2017(6).

[4] http://www.moe.gov.cn/jyb_xwfb/gzdt_gzdt/moe_1485/201705/t20170514_304579.html

[5] Li Peng, Linbai Xie, Zhihai Wu, et al. Research on Talent Cultivation Program of New Undergraduate Students in Internet of Things [J]. Computer Education, 2013(15):77-81.

[6] Yong Wang. Research and Construction of Cultivating Talents for Innovative Engineering Talents in Science and Engineering [J]. Computer Education, 2013(8):15-18.

[7] Hui Chen, Jingzhao Li, Lin Zhan. Research on Talent Cultivation and Specialty Construction of Internet of Things [J]. Computer Education, 2014(4):13-17.

[8] Jingxian Chen, Zhisheng Chen. Construction and Application of Internet of Things Laboratory in Colleges and Universities [J]. Laboratory Research and Exploration, 2013(8).

[9] Hongyan Qian, Bing Chen, Xuefeng Yan. Research on the Teaching Practice System of Internet of Things [J]. Computer Education, 2011(23):21-25.

[10]Gaofeng Luo, Zijuan Shi. A Study on the Practice Model of Internet of Things Teaching - A Case Study of Internet-based Curriculum Practical Teaching Based on Open Platform [J]. IoT Technology, 2016, 6(7):108-109.

[11]Xiaolong Xu, Weifeng Lu, Geng Yang. Research on the Strategy of Cultivating Professional Talents in Internet of Things [J]. Journal of Nanjing University of Posts and Telecommunications (Social Science Edition), 2012, 14(1):119-124.

[12]Lalin Jiang, Jing Wang, Weihong Xu. Research on the Course Reform of Internet Engineering Specialty [J]. Computer Education, 2011(19):48-50.

[13]Gongyi Wu. Reflections on the Construction of Teaching System of Internet of Things Engineering [J]. Computer Education, 2010(21):26-29.

[14]Zhongmei Ma, Juan Sun, Qi Li. Discussion on Curriculum System and Practice of Internet of 
Things Engineering [J]. Application of Single Chip Microcomputer and Embedded System, 2011, 11(10):1-4.

[15]http://tech.ifeng.com/a/20160612/41621579_0.shtml

[16]Ce Zhang, Dianhui Chu, Fanchao Meng, et al. Teaching Research on IoT and Embedded System of Software Engineering. Computer Education, 2016, 8(8): 19-25. 